\title{
Gas Sensing Characteristics of Low-powered Dual MOSFET Hydrogen Sensors
}

\author{
Bum-Joon Kim, Jin-Ho Yoon, Jung-Sik Kim* \\ Department of Materials Science and Engineering, University of Seoul, Seoul, 130-743, Korea, \\ *jskim@uos.ac.kr
}

\begin{abstract}
A low-powered hydrogen sensitive dual-MOSFET device was designed, fabricated and characterized for self compensation to electric signal degradation. Differential outputs in both sensitive and reference FETs were stable for changes in the outer environments due to the same dependence of the electrical characteristics. The proposed sensor design showed low power consumption $\left(45.5 \mathrm{~mW}\right.$ at $\left.150^{\circ} \mathrm{C}\right)$ by achieving complete heat isolation. Stable responses to $\mathrm{H}_{2}$ gas were observed over a range of temperatures and the optimal point in the micro-heater operation was approximately $150^{\circ} \mathrm{C}$ (The highest sensitivity was $111.17 \mu \mathrm{A}$ to $5,000 \mathrm{ppm} \mathrm{H}_{2}$ gas, the response and recovery times were $18 \mathrm{sec}$ and $19 \mathrm{sec}$, respectively.). From the experimental results, the increased sensitivity to various $\mathrm{H}_{2}$ concentrations corresponded to the Langmuir relationship.
\end{abstract}

Key words: gas sensor, hydrogen, MOSFET, low power and silicon micromachining

\section{Introduction}

Hydrogen gas monitoring has attracted considerable interest in many fields, such as the chemical industry, semiconductor manufacturing process and fuel cells, mainly for gas leak detection and monitoring [1]. Hydrogen sensors based on $\mathrm{Pd}$ - MOS field effect transistors have been used over the past 35 years [2,3]. Some research groups have recently worked on thermally isolating the electronic components on the membranes by silicon micromachining and CMOS technologies $[4,5]$, but few have examined MOSFET-type gas sensors. Previous studies utilized SOI (Silicon on Insulator) wafers, which were unsuitable for the low cost gas sensor fabrication, and two process steps for the thermal isolation structures, which were quite difficult fabrication process. For these reasons, this study proposed a simple route for thermally isolated sensing components in a MOSFET type gas sensor chip frame via a modification of the two step bulk micro-machining process.

In this study, a compensation method was developed using a reference FET with no hydrogen gas response and a sensitive FET with the same electrical performance. The electrical characteristics, thermal properties and hydrogen gas sensing performance were analyzed in the fabricated sensors.

\section{Experimental}

A compensation method was developed using a sensitive component for hydrogen sensing and a reference with the same electrical characteristics. Figure 1 shows the low powered dual-MOSFET sensor. The FET with the same gate metal, which had an identical work function, was unaffected by hydrogen gas, and was integrated with a gas sensitive-FET. To control the operation temperature, a microheater was integrated into the sensor chip using the same gate material, $\mathrm{Pt}$ thin film, for the simple fabrication steps. The entire fabrication process was accomplished using six masks for the photolithography steps. These six lithography masks were prepared to develop gas sensor fabrication processes for Arsenic ion implantation and diffusion, gate insulation layer $\left(\mathrm{SiO}_{2}\right)$, gate and metal contact line $(\mathrm{Pt}$ pattern), passivation layer, and bulk micromachining patterns. A discrete silicon island structure was produced by two successive micromachining process-steps to reduce the heat loss inside the dielectric membrane [6].

The gas sensing measurements were performed in a continuous gas flow system to control the $\mathrm{H}_{2}$ gas concentration. The gas sensing signals to $\mathrm{H}_{2}$ gas were examined by measuring the drain current changes in the output curves $\left(V_{D S}-I_{D}\right)$. 


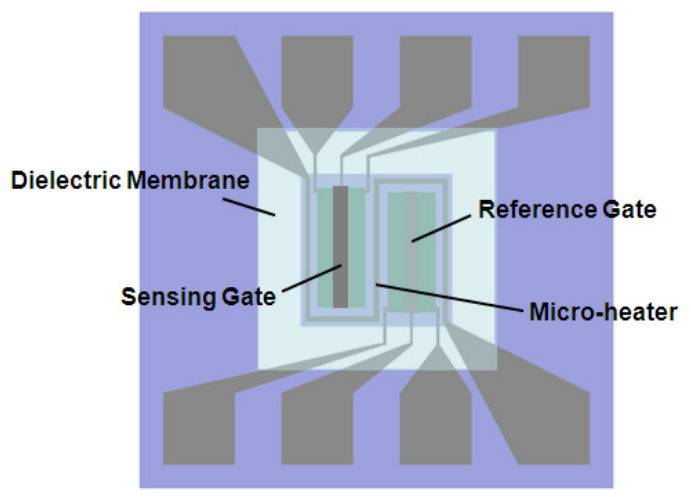

(a)

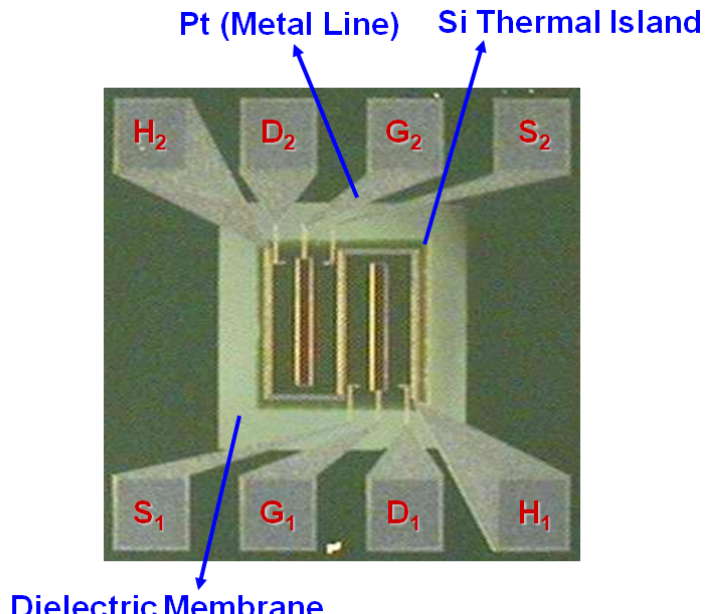

(b)

Fig. 1. Low powered dual-MOSFET sensors: (a) the schematic diagram, and (b) photographs of the fabricated sensor device.

The hydrogen response was measured using voltage follower circuits to determine the changes in the drain current of both FET devices. The gas sensing properties to $\mathrm{H}_{2}$ gas $(5,000 \mathrm{ppm})$ were analyzed at sensing element temperatures from room temperature to $250{ }^{\circ} \mathrm{C}$. The gas responses to various $\mathrm{H}_{2}$ concentrations were also evaluated from $100 \mathrm{ppm}$ to 10,000 ppm of $\mathrm{H}_{2}$ gas at the optimum operating temperatures

\section{Result and Discussion}

The thermal mass and power dissipation of the sensor were minimized by the thermal island design. To increase the heating efficiency, dual (sensing/reference) FETs and a heater were located in a silicon island isolated from the chip frame by a dielectric membrane. The effect of the silicon island structure was examined using a FEM simulation. Precise temperature control of the sensing element and the power consumption of the fabricated sensor device were achieved using a micro-heater operation. The fabricated sensor device showed low power consumption; $45.5 \mathrm{~mW}$ and $68.4 \mathrm{~mW}$ at $150^{\circ} \mathrm{C}$ and $200^{\circ} \mathrm{C}$, respectively. This shows that the proposed sensor design could achieve the thermal isolation and reduce the heat loss by $\mathrm{Si}$ thermal island formation through two successive bulk micromachining steps.

At the gas sensing characterization for $\mathrm{H}_{2}$ gas $(5,000 \mathrm{ppm})$ in Figure 2, the changes in the drain currents of the sensing FET were 54.41 $\mu \mathrm{A}, 60.17 \mu \mathrm{A}, 83.72 \mu \mathrm{A}, 111.17 \mu \mathrm{A}, 74.11 \mu \mathrm{A}$ and $70.50 \mu \mathrm{A}$ at a micro-heater temperatures of room temperature, $50^{\circ} \mathrm{C}, 100^{\circ} \mathrm{C}, 150^{\circ} \mathrm{C}, 200^{\circ} \mathrm{C}$, and $250^{\circ} \mathrm{C}$, respectively. In particular, the drain current changes increased gradually with increasing temperature of approximately $150^{\circ} \mathrm{C}$, but the gas sensing signals decreased at high temperatures. As shown in Figure 3, the response and recovery times also appeared to be shorter at $150^{\circ} \mathrm{C}$ than at the other temperatures. From these experimental results, the sensor operation at $150^{\circ} \mathrm{C}$ showed the best performance to hydrogen gas due to the highest sensitivity and stable response/recovery characteristics at this temperature.

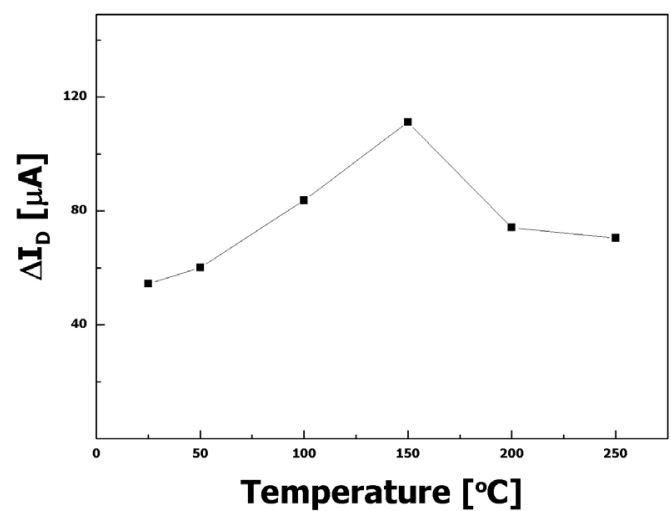

(a)

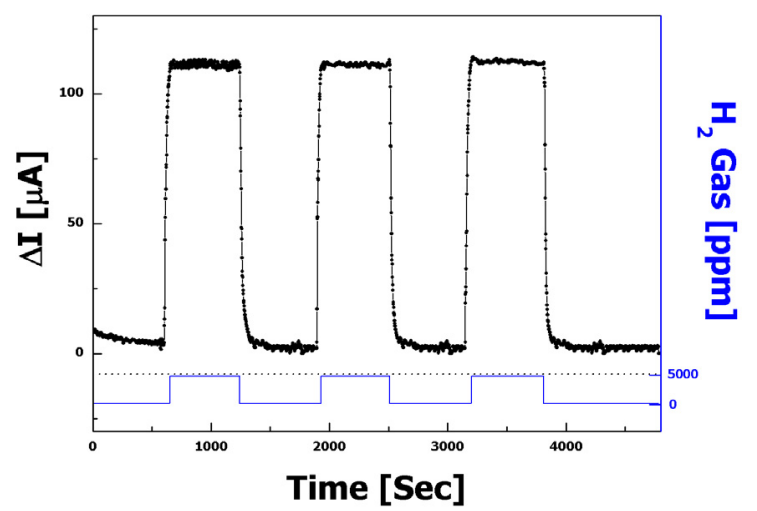

(b)

Fig. 2. Gas sensing characteristics of the dual-FET sensors: (a) drain current changes at various operating temperatures, and (b) transient responses for $5,000 \mathrm{ppm} \mathrm{H}_{2}$ gas injections at $150^{\circ} \mathrm{C}$. 




Fig. 3. Gas sensing characteristics of the dual-FET sensors at various operating temperatures: data plots for the comparison of response/recovery times (at 5,000 ppm $\mathrm{H}_{2}$ gas injections)

Figure 4 shows the drain current change with various hydrogen concentrations from 100 to $10,000 \mathrm{ppm}$. The sensor operation temperature was $150{ }^{\circ} \mathrm{C}$, and the sensor signal increased with increasing hydrogen concentrations. At all gas concentrations tested, the signals were achieved quickly a steady state. The gas sensitivities to $\mathrm{H}_{2}$ gas at concentrations of 100 , $500,1,000,2,000,5,000$, and 10,000 ppm were $8.46 \mu \mathrm{A}, 16.38 \mu \mathrm{A}, 31.27 \mu \mathrm{A}, 67.24 \mu \mathrm{A}, 111.17$ $\mu \mathrm{A}$, and $167.81 \mu \mathrm{A}$, respectively. The dotted line in the figure corresponds to the Langmuir relationship expressed simply as;

$$
\Delta \mathrm{I}_{\max }=\Delta \mathrm{I}_{\max } \frac{\sqrt{C / C_{0}}}{1+\sqrt{C / C_{0}}}
$$

where $\Delta \mathrm{I}_{\max }$ represents the maximum value of the drain current change, $\mathrm{C}$ is the hydrogen concentration in dry air and $\mathrm{C}_{0}$ is a hydrogen concentration at $\Delta \mathrm{I}=\Delta \mathrm{I}_{\max } / 2$. Both $\Delta \mathrm{I}_{\max }$ and $\mathrm{C}_{0}$ might be obtained by fitting the experimental values.

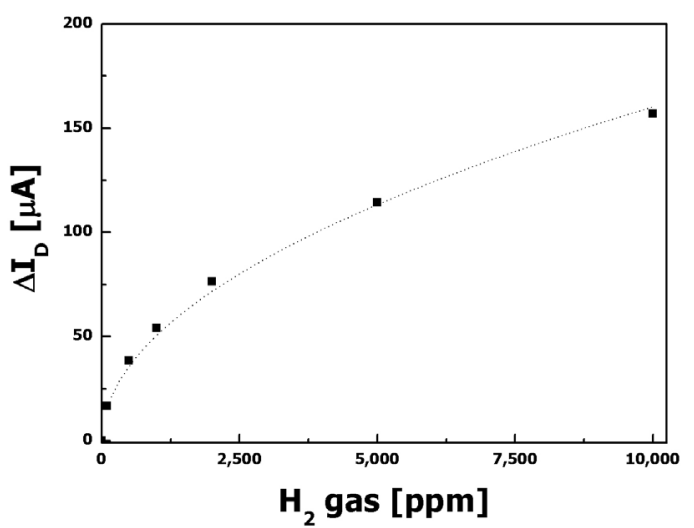

Fig. 4. Gas sensing characteristics of the dual-FET sensors at various $\mathrm{H}_{2}$ gas concentrations.

\section{Conclusion}

The dual-gate FET hydrogen sensor was integrated with a micro-heater and two Pt-gate FETs (sensing/reference devices) for hydrogen detection. The identical output of the sensitiveFET and reference-FET contributed to the stable output in the higher temperature ranges. The proposed sensor design could achieve complete thermal isolation inside the dielectric membrane. The optimal operating point of the Pt-FET sensor was approximately $150^{\circ} \mathrm{C}$, showing the highest sensitivity $(111.17 \mu \mathrm{A})$ to $5000 \mathrm{ppm} \mathrm{H}_{2}$ gas, as well as a faster response and recovery (18 sec and $19 \mathrm{sec}$ ) than at other temperatures. The increased sensitivity for various $\mathrm{H}_{2}$ concentrations corresponded to the Langmuir relationship. The dual MOSFET $\mathrm{H}_{2}$ gas sensor is suitable for a range of applications in several fields because of its lowpower consumption, thermal stability and rapid response/recovery performance.

\section{Acknowledgements}

This research was supported by a grant from the Fundamental R\&D Program for Core Technology of Materials funded by the Ministry of Knowledge Economy, Republic of Korea, in 2008.

\section{References}

[1] C. Christofides, A. Mandelis, Solid-state sensors for trace hydrogen gas detection, Journal of Applied Physics, 68, 1-30 (1990); doi: 10.1063/1.346398

[2] I. Lundström, S. Shivaraman, C. Svensson, L. Lundkvist, A hydrogen-sensitive MOS field-effect transistor, Applied Physics Letter, 26, 55-57 (1975); doi: 10.1063/1.88053

[3] K. Tsukada, T. Kiwa, T. Yamaguchi, S. Migitaka, Y. Goto, K. Yokosawa, A study of fast response characteristics for hydrogen sensing with platinum FET sensor, Sensors and Actuators B, 114,158-163 (2006); doi: 10.1016/j.snb.2005.04.026,

[4] P. K. Guha, S. Z. Ali, C.C.C. Lee, F. Udrea, W.I. Milne, Novel design and characterisation of SOI CMOS micro-hotplates for high temperature gas sensors, Sensors and Actuators B, 127, 260-266 (2007); doi: 10.1016/j.snb.2007.07.047

[5] D. Briand, H. Sundgren, B. Schoot, I. Lundstrom, N. F. Rooij, Thermally isolated MOSFET for gas sensing application, IEEE Electron Device Letters, 22, 11-13 (2001); doi: $10.1109 / 55.892428$

[6] D. Resnik, D. Vrtacnik and U. Aljancic, S. Amon, Wet etching of silicon structures bounded by (311) sidewalls, Microelectronic Engineering, 5152, 555-566 (2000); doi: 10.1016/S01679317(99)00519-5 